\title{
Discussion on the Cost Budget of Construction Enterprises
}

\author{
Haiyan Sui ${ }^{1} \&$ Yuqi Wang ${ }^{1}$ \\ ${ }^{1}$ School of Finance and Economics, Shandong Jiaotong University, Jinan, China \\ Correspondence: Haiyan Sui, School of Finance and Economics, Shandong Jiaotong University, No.5001, Haitang \\ Road, Changqing University Science \& Technology Park, Jinan City, Shandong Province, China. Postcode: 250357. \\ Tel: 86-1861-541-6926. E-mail: suihy77@163.com
}

Received: May 17, 2013

Accepted: June 4, 2013

Online Published: June 7, 2013

doi:10.5430/bmr.v2n2p85

URL: http://dx.doi.org/10.5430/bmr.v2n2p85

\begin{abstract}
With the fast development of the real estate market and the urbanization, the cost budget of construction enterprise has attracted more and more attentions. Despite the interest for the cost budget of construction enterprise, academic research on this topic is limited. This paper aims at studying the measures to solve the major problems existing in the cost budget of construction enterprises based on the analysis of the causes of those problems.
\end{abstract}

Key words: Construction Enterprise, Cost, Cost Budget

\section{Introduction}

\subsection{Cost of Construction Projects}

The cost of construction projects is the value of necessary resources and labor power expressed in the amount of money which is based on accounting for the construction projects. (e.g., Zheng, 2010)

As for accounting for the construction enterprises, the cost of construction projects is narrowly defined as the sum of all expenditures directly related to the engineering constructions. Those not directly related to the engineering constructions are expensed.

The cost of construction projects can be divided into direct and indirect cost. Direct cost is the cost which can be included in the objects of cost accounting, such as labor cost, material cost, machinery use fee etc. However, indirect cost refers to the expenditures which cannot be included in the objects of cost accounting and should be allocated to the relevant cost object, such as field overhead etc.

\subsection{Cost Budget of Construction Enterprises}

The cost budget of construction enterprises generally is a budget for all cost of the project. It's the cost plan made for the project which is used to measure and monitor the implementation of the cost ( e.g., Han , 2012).We believe that cost budget of construction enterprises is a cost budget of needed materials, labor costs and other indirect costs which can be finally expressed in monetary. Combined with the cost budget plan, it has a supervising and controlling effect on the actual cost.

Cost budget can be divided into prior budget, concurrent budget and post budget. Although the prior budget is the most important one, the concurrent budget during the constructing process is very necessary because the prior budget is not perfect and there might be unexpected budgeting items or large deviation between the actual cost and capital budgets. Moreover, the post budget can help us to fully know the budgeting problems and the corresponding solving measures of the project and learn experiences and lessons as references for the future budget.

\section{Discussions}

Nowadays, a lot of construction enterprises overspent on the construction but produced very low profits or even losses. And even worse, some projects were shut down in the midway. That is largely due to the weakness of cost budget.

\subsection{Low personnel quality of cost budget}

The budget of construction enterprises is a relatively complex one, which includes all of the production costs, labors, materials, machineries, wages, bonuses and so on. Therefore, the specialists with high professional quality and scientific technologies who are familiar with the laws and regulations of our country are required. However, the cost 
budgeters of some construction enterprises are not well qualified, or they have no capacity for cost budgeting. For example, the budget based on insufficient evidences can lead to a serious shortage of funds in the construction process which affects the progress of projects and even the quality of projects. On the other hand, it may lead to capital surplus, which provides an opportunity for the corruption.

\subsection{Defective budget system for materials and machineries}

Direct cost occupies a large proportion of the total construction cost. But the budget for direct cost is not accurate because of the defective budget system. Some cost budgeters, just for simple and convenient, fabricate a price to determine the material cost without sufficient research which leads to the great gap between the budget and the actual cost. Some cost budgeters do not know the equipments required for the project which results in buying many needless equipments or borrowing a great many from other projects as standby equipments. It's a great waste of money and increases the cost of the project.

\subsection{Unreasonable design of construction scheme}

Nowadays, many designers do not really know what kind of cost will actually happen in the whole construction and they borrow or apply mechanically the design drawings of others in order to reduce the workloads. Such unreasonable design schemes lead to a disorder construction site which definitely increase the construction cost. In addition, the indeterminate construction scheme causes a great deviation between the real cost and the planned cost in the construction process. It also has a great negative impact on the budget formulation and effective implementation.

\subsection{Lack of awareness about cost budget management and control}

The division of labor seems too clear in the construction enterprises because when the budget is finished, any errors and problems that occur in future budget implementation of projects have nothing to do with the designers. The departments that play a decisive role in the implementation of the project, such as material purchasing department, ignored the existed budget with no awareness of budget control. Not only that, the budget management awareness is also very weak and they don't play a role in adjusting the unity and cooperation of different departments.

\subsection{Weak safety awareness}

There are many hidden dangers in construction site due to the weak safety awareness. Some construction personnel do not comply with the construction disciplines and some do not take effective safety measures, such as not wearing helmets, not using machinery and equipment in accord with the prescribed procedures which increases the safety accident rate, the fees paid, the artificial damage compensation fees, the labor costs, and even affects the progress of the project. If the accident happens, it would inevitably lead to big deviation between the budget and the actual settlement price and greatly increase the budget difficulties.

\section{Measures}

\subsection{Increasing the cost budget personnel quality of construction enterprises}

The budget is an industry with particularly high technicality and expertise which is especially important to the construction enterprises. It requires cost budget personnel not only have strong professional knowledge, but also have a well-understanding of project-related policies, relevant laws and regulations of our country. At the meantime, more experiences are needed. Cost budgeting personnel must not only understand the financial knowledge, but also master the knowledge of engineering drawings, engineering materials and engineering construction methods. Therefore, on the premise of choosing excellent talents, it is crucial to strengthen and pay attention to the training and learning for them. At the same time, in order to produce greater profits with least cost, it is very important and necessary for budget personnel to go to field frequently rather than being an armchair strategist. What the budget personnel should do includes observing and investigating the construction environment, discussing the construction scheme, understanding the current construction budget quota, making reasonable guess based on objectively analyzing the impact of the price on the project cost, realizing the cost changes of the construction site timely to modify the budget scheme reasonably, and learning more knowledge of engineering. Only in this way can the cost budget personnel actually play their roles.

\subsection{Designing the budget scheme of materials and machineries based on market research}

Budget personnel should be fully aware of the market price of materials and predict the price trend on the basis of their market research before making a cost budget plan. Considering the time value and other factors, they also should try to reduce the fund as possible as they can. Besides, they should determine the quantities and batches of goods and consider the reasonable loss of the materials. The communication between the budgeters and the 
purchasers is without doubt necessary for narrowing the gap between the budget and the actual cost. It is significant to consider the future using value of the machineries to decide whether to buy or rent based on the analysis of various factors before buying them. The budget personnel should also make reasonable estimates on the equipment repair and maintenance expenditures and pay attention to the details which will make the cost budget more and more effective.

\subsection{Designing a clear and detailed construction scheme}

There is a great relationship between the success (or failure) of the cost budget and the scheme of the designer. So, the designing work should attract more attentions in order to enhance the accuracy of cost budget. The designer has to go to the construction field and fully communicate with constructors to make the designing purpose clear. The construction scheme should be precise and detailed. Only in this way can it reduce the redoing situation.

\subsection{Strengthening the execution and management power of cost budget}

The implementation of the cost budget is a systematic process and requires the involvement and cooperation of the relevant departments and persons. The implementation is required to be based on the budget. The cost spending should be in accordance with the standards and scopes of the cost budget. Only in this way will the budget implement as far as possible and the funds be allocated reasonably to achieve maximum benefits. Furthermore, the manager must play a role in the budget supervision and management. Only by the different departments making efforts together will the cost budget play a real role in controlling and reducing costs.

\subsection{Enhancing safety awareness}

In order to reduce unnecessary accidents, it is necessary for the construction enterprises to frequently educate the constructors about safety to improve their safety consciousness. The training of professional machine operating skills is also required in order to help the operator develop a good habit. In addition, the management should increase penalties on the workers who always make mistakes. Anyway, the construction enterprises should try their best to confine the accident rates to a reasonable scope and narrow the gap between the budget and the actual cost.

\section{Conclusions}

Cost budget is a very difficult and complicated issue in many construction enterprises. Every aspect such as the cost budgeters, the cost budget methods and the cost budget supervisions needs to be improved. The accomplishment of the cost budget plan requires the participation, communication and collaboration of all staffs in the construction enterprises. It is beneficial to make analysis of the differences between the prices in the cost budget and the final settlement prices and find the causes of overspends or savings.

\section{References}

Feng Luo \& Zhenrong Lv. (2011). Discussion on the Budget Management of Highway Project", Heilongjiang Transportation Science and Technology, 9, 347. http://dx.doi.org/10.3969/j.issn.1008-3383.2011.09.281

Jingping Che. (2010). Measures of Strengthening the Cost Control of Construction Enterprises, Money China (Academic Edition ), 11, 100. http://dx.doi.org/10.3969/j.issn.1009-2781.2010.22.073

Junying Zheng. (2010). Strategy Analysis on the Building Engineering Budget Problems. Modern Economic Information, 5, 77. http://dx.doi.org/10.3969/j.issn.1001-828X.2010.05.057

Suyan Wang. (2010). Discussion on Designing Project Budget Based on the Project Method, Value Engineering, 32, 114. http://dx.doi.org/10.3969/j.issn.1006-4311.2010.32.081

Xiaoqun Han. (2012). Importance of the Cost Budget of Construction Enterprises, China Market, 23, 38-39. http://dx.doi.org/10.3969/j.issn.1005-6432.2012.23.015 